\title{
Incarceration of a paraoesophageal hiatus hernia
}

\author{
Keith Siau • Arun Khanna • Taiceer Abdul-Wahab
}

Received: 27 November 2009 / Accepted: 6 September 2010 / Published online: 23 October 2010

(C) The Author(s) 2010. This article is published with open access at Springerlink.com

An 81-year-old woman was admitted with a 1-week history of breathlessness. On admission, she was found to be in respiratory distress with new onset atrial fibrillation and hypotension. Her chest X-ray (Fig. 1) revealed a large hiatus hernia with a dual-fluid level, associated with significant extension into the left hemithorax and mediastinal shift. She was admitted to a general medical ward, where care was focused on controlling her atrial fibrillation. Overnight, she developed hypoxaemia and was found to be in severe type 2 respiratory failure. Following a review of her chest X-ray, she was referred for urgent laparotomy, which disclosed an incarcerated hiatus hernia with extensive mucosal necrosis. Following partial gastrectomy and supportive care, she made a steady recovery. Although hiatus herniae are common, incarceration is a rare complication of paraoesophageal herniae. Patients presenting with such features on chest X-ray, even in the absence of gastric outlet obstruction, should be referred for urgent surgical intervention.

K. Siau $(\bowtie) \cdot$ A. Khanna $\cdot$ T. Abdul-Wahab Department of Medicine, Great Western Hospital,

Marlborough Road,

Swindon SN3 2AU, UK

e-mail: keith@siau.org
A. Khanna
e-mail: arunkhanna@tst.nhs.uk
T. Abdul-Wahab
e-mail: taiceer.abdul-wahab@gwh.nhs.uk

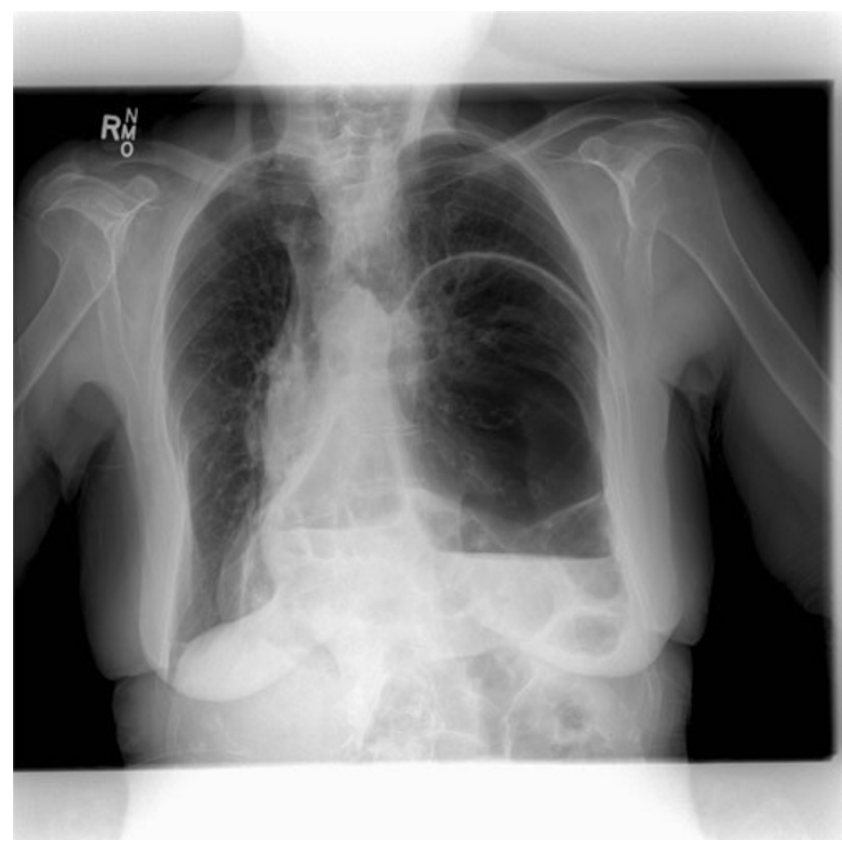

Fig. 1 Chest X-ray revealing a large hiatus hernia with a dual-fluid level, associated with significant extension into the left hemithorax and mediastinal shift

Open Access This article is distributed under the terms of the Creative Commons Attribution Noncommercial License which permits any noncommercial use, distribution, and reproduction in any medium, provided the original author(s) and source are credited. 